\title{
Use of non-integrating $Z m$-Wus2 vectors to enhance maize transformation
}

\author{
Non-integrating WUS2 enhances transformation
}

\author{
George Hoerster ${ }^{1}$. Ning Wang ${ }^{1} \cdot$ Larisa Ryan $^{1} \cdot$ Emily Wu $^{1} \cdot$ Ajith Anand ${ }^{1} \cdot$ Kevin McBride $^{1} \cdot$ Keith Lowe $^{1}$. \\ Todd Jones $^{1} \cdot$ Bill Gordon-Kamm ${ }^{1}$ (i)
}

Received: 23 May 2019 / Accepted: 9 December 2019 / Published online: 2 January 2020 / Editor: Charles Armstrong

(C) The Author(s) 2020

\begin{abstract}
The use of Baby boom (Bbm) and Wuschel2 (Wus2) has made maize transformation more efficient across an increasingly wide range of inbreds. However, the benefits have come with the requirement of excising these transformation helper components to enable plant regeneration, which adds size to the T-DNA, and complexity to the transformation system. A new system with the advantages of smaller size and simplicity for the selectable marker gene-containing T-DNA is described. First, expression of Zm-Wus 2 alone driven by the maize Pltp promoter (Zm-Pltp pro), was determined to be sufficient to induce rapid somatic embryo formation from the scutella of maize immature embryos. It was also demonstrated that co-infecting with two strains of Agrobacterium, one with a Wus 2 expression cassette, and the other with a combination of both selectable and visual marker cassettes, produced transformed T0 plants that contained only a single copy of the selectable marker T-DNA, without the integration of Wus2. Furthermore, the process was optimized by varying the ratio of the two Agrobacterium strains, and by modulating Wus 2 expression to enable high-frequency recovery of selectable marker-containing T0 plants that did not contain Wus2. Several factors may have contributed to this outcome. Wus2 expression in localized cell(s) appeared to stimulate somatic embryogenesis in neighboring cells, including those that had integrated the selectable marker. In addition, in cells in which the Wus 2 T-DNA did not integrate but the selectable marker T-DNA did, transient Wus 2 expression stimulated somatic embryo formation and regeneration of stable T0 plants that contained the selectable marker. In addition, augmenting the Pltp promoter with three viral enhancer elements to increase Wus2 expression stimulated embryogenesis while precluding their regeneration. The phenomenon has now been designated as "altruistic transformation."
\end{abstract}

Keywords Zm-WUS2 - somatic embryo formation · maize transformation · Agrobacterium

\section{Introduction}

The transcription factors Baby boom $(\mathrm{Bbm})$ and Wuschel2 (Wus2), which are also referred to as morphogenic genes, greatly enhance maize transformation (Lowe et al. 2016). Furthermore, spatio-temporal regulation of morphogenic gene expression by the maize Pltp promoter stimulate rapid (3-7 d post infection), and direct formation of somatic embryos from immature scutella

Electronic supplementary material The online version of this article (https://doi.org/10.1007/s11627-019-10042-2) contains supplementary material, which is available to authorized users.

Bill Gordon-Kamm

william.gordon-kamm@corteva.com

1 Corteva Agriscience, Johnston, IA, USA
(Lowe et al. 2018). The somatic embryos can be directly germinated into transgenic plants and bypass the need for callus initiation and maintenance. The use of $N_{o s}$ pro:Wus 2 plus $U b i_{\text {pro }}:: B b m$ has been used to stimulate embryogenic callus formation in the public inbred B73 (Mookkan et al. 2017). More recently, Axig $1_{\text {pro: }}:$ Wus 2 plus Pltp pro $_{\text {: }}$ Bbm has been shown by Lowe et al. (2018) to stimulate somatic embryo formation in B73, Mo17, and Fast Flowering Mini Maize (FFMM germplasm developed by McCaw et al. 2016). While resultant T0 plants that contained a single copy (SC) of the T-DNA with Bbm and Wus2 were fertile and had a normal phenotype, ectopic expression of transcription factors can have subtle pleiotropic effects (Lowe et al. 2016, 2018). For example, expression of $C R C$ (a fusion between two transcription factors, known as $R$ and $C 1$, which activates the anthocyanin pathway) in maize, induces the expression of hundreds of genes (Bruce et al. 
2000). Therefore, removal of the morphogenic genes is desirable for both transgene testing and commercial product development. Alternatively, transient expression of morphogenic genes from a T-DNA that is unlinked to a second T-DNA, which contains a selectable marker cassette and a visual marker cassette (referred to as the "Selectable" T-DNA), could offer a viable alternative to gene excision. This simplifies both vector construction and the downstream processes to produce transgenic or genome-edited plants.

Agrobacterium-mediated T-DNA transformation involves transient T-DNA gene expression within 36-48 h post infection, followed by stable T-DNA integration into the plant genome (Yoshioka et al. 1996; Gelvin 2003). This has been elegantly demonstrated using $C R E$-mediated excision of a genomic locus flanked by homologous loxP sites, without stable integration of the T-DNA harboring the CRE recombinase gene (De Buck et al. 2000). This was achieved by co-infection with two Agrobacterium strains, one containing a binary plasmid carrying the CRE recombinase, and the other strain carrying an excisable GUS construct linked to a NPTII cassette (De Buck et al. 2000).

In this study, a transformation method that exploits transient T-DNA expression to recover stable T0 plants using morphogenic genes is described. This development was predicated by the observation that a strong pulse of Wus2 expression by the maize Pltp promoter was sufficient to rapidly stimulate somatic embryo formation and T0 plants. By using two Agrobacterium strains for transformation, one strain containing a T-DNA binary plasmid with a Wus 2 expression cassette, and a second strain containing a binary T-DNA plasmid with both a selectable and visual marker (referred to as the "Selectable T-DNA"), Wus2-mediated growth stimulation was provided in trans to cells containing the Selectable gene. Optimally, the strain containing Wus2 T-DNA was present at a lower concentration relative to the strain containing the Selectable T-DNA. Using this mixture of Agrobacterium strains for transformation, transient expression of Wus 2 improved the frequency of regenerated stable T0 plants that contained only the Selectable T-DNA without stable integration of the Wus2 transgene. The level of transient Wus2 expression and the concomitant stimulation of somatic embryo formation in surrounding cells could be increased further, by positioning three viral enhancer elements in front of the Pltp promoter. This positioning provided the added benefit of increasing Wus2 expression, which provided additional insurance that Wus2-expressing cells would inhibit their own regeneration. This method is hereby referred to as "altruistic transformation."

\section{Materials and methods}

Transformation and PCR analyses All transformation experiments and qPCR analyses were done as described previously (Lowe et al. 2018) with minor modifications.
Plant material The Pioneer maize (Zea mays L.) inbreds used in this study included both temperate inbreds (the non-stiffstalk HC69, and stiff-stalks PH1V69 and PHW52), and tropical inbreds (non-stiff-stalks PH4BAH and PH2KD1, and stiff-stalks PH28SV, PH2Y8G, and PH4B9Z). These inbreds or suitable related germplasm will be provided under an applicable Material Release Agreement. All plants used for source immature embryos were grown in the greenhouse.

Culture media used for transformations and plant regeneration All media recipes are described by Lowe et al. (2016) and Jones et al. (2019), with minor modifications to media components as listed in Supplemental Table S-1, with all ingredients and sources listed in Table S-9. For selection, $0.1 \mathrm{mg} \mathrm{L}^{-1}$ imazapyr was present in the somatic embryo formation medium (13329) or $150 \mathrm{mg} \mathrm{L}^{-1} \mathrm{G} 418$ was substituted for imazapyr.

Agrobacterium-mediated transformation Expression components such as promoters, structural genes, terminators, and enhancer elements are listed in Supplemental Table S-2. All transformations were completed using the thymidine auxotrophic Agrobacterium strain LBA4404 THY, which contained pVIR9 (PHP71539), (Anand et al. 2018) at $\mathrm{OD}_{550}$ of 0.5. For mixtures of two Agrobacterium strains containing different TDNAs, each strain was brought to the appropriate optical density and mixed at different ratios (1:1, 9:1, and 99:1), before infecting the immature embryos. Agrobacterium with different T-DNAs in the binary plasmid are referred to as "strains." Two selectable markers were used in experiments: a sulfonylurea herbicide resistance marker 'Hra' (Green et al. 2009), driven by the sorghum ALS promoter (see Supplemental Table S-2), was used for selection with $0.1 \mathrm{mg} \mathrm{L}^{-1}$ imazapyr in both the maturation and rooting medium, or the $U b i_{p r o}:$ :NPTII gene was used with $150 \mathrm{mg} \mathrm{L}^{-1} \mathrm{G} 418$ in both the maturation and rooting medium (13329 and 13158 media, respectively). Constructs used in this study are shown in Figs. 1, 2, 4, 5, 6 and 7, and the individual components are described in Table S-2. The maize Axig1 and Pltp promoters (auxin-induced and scutellum/callus-preferred, respectively) used in this study to drive expression of Wus2 and $\mathrm{Bbm}$ have been previously described (Lowe et al. 2018). For two plasmids, PHP87598 and PHP88158, an expression cassette was added using a constitutive Nos promoter driving expression of $C R C$, which is a fusion of the maize $C l$ and $R$ transcription factors, which when expressed together activate the pathway for anthocyanin production (Bruce et al. 2000). T-DNA sequences for plasmids used in these experiments have been deposited in Genbank under the following accession numbers: PHP80770 (MN380778), PHP83623 (MN380779), PHP83027 (MN380780), PHP83621 (MN380781), PHP86491 (MN380782), PHP81561 (MN380783), PHP80912 (MN380784), PHP87078 (MN380785), 
a) PHP80770 (Control)

\begin{tabular}{|c|c|c|c|c|c|}
\hline RB $A x i g 1_{p r o}:: W u s 2$ & Pltp pro: $: B b m$ & $G \mid b 1_{\text {pro }}:: C R E$ & $Z \mathrm{~m}-\mathrm{Ubi}_{\mathrm{pro}}:: D s R E D 2$ & $S i-U b i_{\text {pro }}:: Z S-G R E E N$ & $S b-A / s_{\text {pro }}:: H r a$ \\
\hline
\end{tabular}

b) PHP 83623

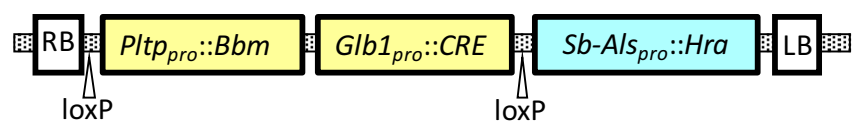

c) PHP83027

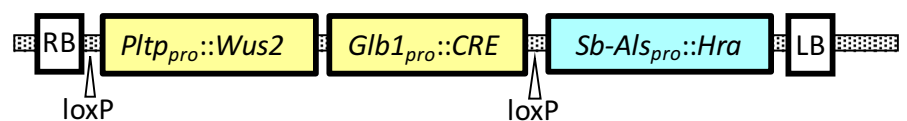

d) PHP83621

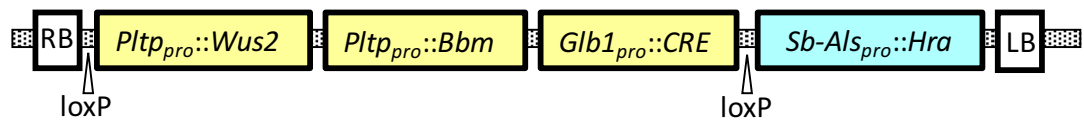

Figure 1. Constructs containing Wus2 alone, $\mathrm{Bbm}$ alone, or in combination used in the experiments summarized in Table 1 below. Yellow boxes indicate excised using $C R E / \mathrm{loxP}$, and blue boxes indicate no excision. Axigl pro is auxin-inducible. Pltp pro is expressed

PHP85848 (MN380786), PHP87598 (MN380787), and PHP88158 (MN380788).

Agrobacterium cultures on solid medium were prepared to ensure that freshly cultured bacterial colonies were growing rapidly immediately before being used for transformation. The Agrobacterium tumefaciens strain LBA4404 THY, which contained both PHP71539 and a separate T-DNA-containing plasmid, was maintained as glycerol stocks and was periodically (every 2-3 wk) streaked out on fresh maintenance medium (Master Medium in Table S-1). The day before using the Agrobacterium for maize transformation, colonies were predominantly in the Zea mays (L) immature embryo scutellum and in callus. $G l b 1_{\text {pro }}$ is a late-embryogenic promoter. $U b i_{\text {pro }}$ and $A l s_{\text {pro }}$ promoters are strong and weak constitutive promoters, respectively.

picked from the Master plate and streaked onto fresh plates containing YP medium (Ishida et al. 1996), on which the bacterium was grown overnight in the dark at $28^{\circ} \mathrm{C}$. The following morning, colonies were collected and suspended in 700A liquid medium.

Maize immature embryos were harvested, typically at 10 $12 \mathrm{~d}$ after pollination with an average length of approximately 1.5-2.0 $\mathrm{mm}$. Immature embryos were isolated and placed into $700 \mathrm{~A}$ medium. Once all of the embryos were harvested from the immature ear, the $700 \mathrm{~A}$ medium was decanted, and the immature embryos were transferred into 700A medium
Figure 2. Contructs containing expression cassettes with the Pltp pro driving expression of $B b m$ (a) or Wus2 (b) used in the experiment summarized in Figure 3. The Bbm and Wus2 expression cassettes are highlighted in yellow because excision was not expected. $\mathrm{Ha}$ $L t p 2_{\text {pro }}$ from barley is aleuronespecific. a) PHP80912

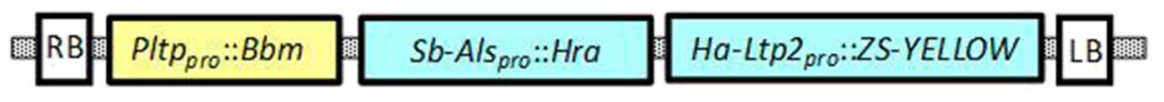

b) PHP85848

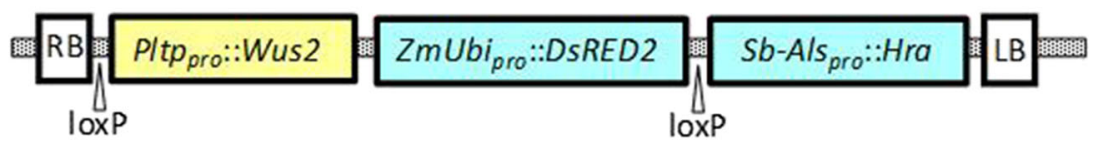


containing freshly suspended A. tumefaciens strain LBA4404 $\mathrm{THY}(\mathrm{OD}=0.5$ at $550 \mathrm{~nm}$ ) or mixtures of strains. After $5 \mathrm{~min}$ in the liquid Agrobacterium suspension, the immature embryos were removed from the liquid and placed scutellum side up on 710I solid medium (co-cultivation medium), overnight at $21^{\circ} \mathrm{C}$ in the dark (for 700A, 700, and 710I media, see Zhao et al. 2002). The following morning embryos were moved onto $605 \mathrm{G}$ somatic embryo induction medium and cultured in dark at $28^{\circ} \mathrm{C}$. After $6-7 \mathrm{~d}$ on $605 \mathrm{G}$ medium, the embryos were moved onto 13329 maturation medium, which contained either $0.1 \mathrm{mg} \mathrm{L}^{-1}$ imazapyr or $150 \mathrm{mg} \mathrm{L}^{-1} \mathrm{G} 418$ (depending on the experiment). After 2-3 wk on 13329 medium, the embryos were moved to 13158 medium that also contained imazapyr (or G418) for rooting and placed under GE Ecolux (General Electric, Boston, MA) fluorescent lights $\left(60 \mu \mathrm{mol} \mathrm{m}^{-2} \mathrm{~s}^{-1}\right)$, with a 16 -h light/8-h dark photoperiod at $26^{\circ} \mathrm{C}$.

Transformation frequency was defined as the number of imazapyr-resistant (or G418-resistant) T0 plants, relative to the total number of infected immature embryos. Imazapyr (or G418) selection was maintained during somatic embryo germination and rooting, to reduce the recovery of escapes (wild-type non-transgenic plants). Once shoots and roots had been established, plantlets were transferred to pots in the greenhouse (procedures for growing maize in greenhouse conditions are well established, see https://docs.lib.purdue.edu/pmcg/).

The JMP Pro 12.2.0 Statistical Discovery software package (SAS Institute Inc., Cary, NC) was used to conduct statistical tests. Data were transformed by arcsine square root transformation, and ANOVA was carried out with the Student's $t$ test for each pair to identify significant differences between means.

Molecular analysis All molecular analyses were completed as described by Lowe et al. (2016). Molecular analysis for transgene copy number was accomplished using qPCR (Wu et al. 2014). In addition to copy number, qPCR data was also used to confirm recombinase-mediated excision based on the absence of loxP-flanked transgenes, and to screen for the presence of Agrobacterium binary vector backbone integration. To prepare genomic DNA samples, the extraction was performed using a single piece (200 $\mathrm{ng}$ ) of fresh leaf tissue from each plant (Truett et al. 2000). Non-transgenic maize inbred lines were used as the negative controls. Quantification was based on detection of amplified gene sequences using genespecific forward and reverse primers, along with the corresponding gene-specific $\mathrm{FAM}^{\mathrm{TM}}$ or Vic ${ }^{\circledR}$-based MGB fluorogenic probes (Applied Biosystems, Waltham, MA). The 2 $-\Delta \Delta$ CT method (Livak and Schmittgen 2001; ABI's user bulletin \#2, www3.appliedbiosystems.com/cms/groups/ mcb_support/documents/generaldocuments/cms_040980. pdf), was used to estimate copy number. For all maize transgenic plants, detection of Agrobacterium vector backbone was based on qPCR screening for sequences from five regions outside of the T-DNA (RB, virG, SPC, Tet, and LB). Plants with negative qPCR signals for all five regions were considered to be backbone-negative. Otherwise, the plants were classified as backbone-positive. Plants with intact single-copy T-DNA integrations without vector backbone were defined as Single-Copy (SC) events.

\section{Results}

The PItp promoter driving Wus2 alone is sufficient to stimulate the direct initiation of somatic embryos Immature zygotic embryos from two maize inbreds HC69 and PH1V69, were transformed with either the control plasmid PHP80770 ( $\mathrm{Zm}$ Axig1 $1_{\text {pro }}:$ Wus $\left.2+Z m-P l t p_{\text {pro }}:: B b m\right)$, or with the test plasmids PHP83623 (Zm-Pltp pro::Bbm), PHP83027 (ZmPltpP $P_{\text {pro }}:$ Wus2), and PHP83621 (Zm-PltpP $P_{\text {pro }}:$ Wus2 + Zm$\left.P l t p_{\text {pro }}:: B b m\right)$, as described in Fig. 1. The T-DNA in all four constructs also carried a $C R E$ expression cassette under the control of the Zm-Globulin1 (Glb1) promoter (Liu et al. 1998), to enable auto-excision of the morphogenic genes and the $C R E$ gene flanked by directly oriented loxP sites (Fig. 1), which has been used previously for excision of the morphogenic genes Zm-Wus2 and Zm-Bbm (Chu et al. 2019). Transformation results for the four vectors are shown in Table 1. Without the Bbm and Wus2 expression cassettes, recovery of transgenic events (without a prolonged callus selection stage), for HC69 typically ranges between 0 and 2\%, and for PH1V69 the frequency is 0 , but for the purpose of this experiment, this treatment was not included.

In maize transformation experiments, differences between genotypes are a common observation, and the overall transformation frequencies for HC69 were higher than for PH1V69 (Table 1). For both maize inbreds, transformation frequencies for Wus 2 alone, or for both combinations of Wus $2+B b m$ produced transgenic events, and the Pltp pro $: \because W u s 2$ treatment produced a similar transformation frequency as the Axig1::Wus $2+$ Pltp pro::BBM treatment for both inbreds. In contrast, using $P_{t t p}$ pro::Bbm alone resulted in a significantly lower transformation frequency for HC69, or no recovery of transgenic events for PH1V69. The treatment in which both Wus2 and Bbm expression were driven by Pltp pro, produced significantly higher transformation frequencies for both inbreds (relative to the other three treatments). For all treatments in both inbreds, the SC frequencies were reduced relative to the total transformation frequencies, but still followed the same trend. When the test vectors were compared with the control plasmid in the two inbreds, the SC frequency ranged between 2 and $4 \%$ for the control, while no SC events were recovered from $\mathrm{Zm}$ Pltp pro::Bbm. In contrast, using Zm-Pltp pro::Wus 2 produced $\mathrm{SC}$ event frequencies ranging from 5 to $10 \%$. Similarly, the Zm-Pltp pro::Wus $2+Z m-P l t p_{\text {pro }}:: B b m$ also produced SC events, 
Table 1. Transformation results for two maize inbreds using Wus2 alone, $\mathrm{Bbm}$ alone, and combinations of Wus 2 plus $\mathrm{Bbm}$. Immature zygotic embryos from two inbreds were transformed with the constructs shown in Fig. 1 (in order for each inbred). T0 plant number and transformation frequencies are shown, including both multi- and single- copy (SC) numbers. The SC event frequency (T0 plants containing a single copy of T-DNA without a vector backbone relative to the total number of immature embryos), were tabulated based on qPCR data. Transformation and single-copy data for individual replicates within each treatment are shown in Table S-3

\begin{tabular}{|c|c|c|c|c|c|c|c|c|}
\hline \multirow[t]{2}{*}{ Inbred } & \multicolumn{2}{|c|}{ Promoters for Morphogenic Genes } & \multirow[t]{2}{*}{ Num. embryo } & \multirow[t]{2}{*}{ Num. T0 plants } & \multirow[t]{2}{*}{$\operatorname{Txn} \%(\bar{x} \pm \mathrm{SD})$} & \multirow[t]{2}{*}{ Sign. diff. } & \multirow[t]{2}{*}{ Num. SC } & \multirow[t]{2}{*}{$\mathrm{SC} \%$} \\
\hline & Wus2 & $B b m$ & & & & & & \\
\hline HC69 & Axig1 $_{\text {pro }}$ & Pltp pro & 388 & 219 & $57.5(6.1)$ & a & 12 & 4 \\
\hline HC69 & & Pltp pro & 148 & 8 & $5.0(2.0)$ & $\mathrm{b}$ & 0 & 0 \\
\hline HC69 & Pltp pro & & 414 & 242 & $57.8(3.4)$ & a & 42 & 10 \\
\hline HC69 & Pltp pro & Pltp pro & 429 & 334 & $77.8(6.0)$ & $\mathrm{c}$ & 58 & 14 \\
\hline PH1V69 & Axigl $_{\text {pro }}$ & Pltp pro & 360 & 31 & $8.8(2.7)$ & $\mathrm{a}$ & 6 & 2 \\
\hline PH1V69 & & Pltp pro & 360 & 0 & 0 & $\mathrm{~b}$ & 0 & 0 \\
\hline PH1V69 & Pltp pro & & 360 & 40 & $11.0(6.1)$ & $\mathrm{a}$ & 18 & 5 \\
\hline PH1V69 & Pltp pro & Pltp pro & 360 & 93 & $23.3(9.5)$ & $\mathrm{c}$ & 40 & 11 \\
\hline
\end{tabular}

Num. embryo $=$ the number of immature embryos infected by the Agrobacterium .

Num. T0 plants $=$ the number of qPCR-confirmed independent T0 plants (transgenic events) recovered per treatment.

$\mathrm{Txn} \%=$ the transformation frequency calculated as (\# T0 plants/Agrobacterium-infected immature embryos) $* 100$.

Num. SC $=$ the number of T0 plants (events) that contained a single copy of the Wus $2 / B b m$ T-DNA.; SC\% $=$ the frequency of single-copy T0 plants relative to the starting number of Agrobacterium-infected immature embryos.

Sign. diff. $=$ signifies whether the means for the treatments within an inbred are significantly different (different letters) or not (same letter) with $p=0.05$

but at higher frequencies of $11-14 \%$ in the two different inbreds. The data suggested the following trends in the two inbreds: (1) transformation frequencies using the control vector $\left(\right.$ Zm-Axig $1_{\text {pro }}:: W u s 2+$ Zm-Pltp $p$ ro::Bbm), were comparable to those using Zm-Pltp pro::Wus2, but the production of SC events was higher for Zm-Pltp pro::Wus2; (2) both Wus2 and Bbm under the control of the Pltp promoter resulted in higher transformation frequencies and SC event frequencies, and in contrast; and, (3) using $Z m-P l t p_{p r o}:: B b m$ resulted in the lowest transformation and $\mathrm{SC}$ event frequency compared with the other constructs.

Mixing an Agrobacterium strain containing $\mathrm{Zm}$ Pltp $p$ ro: Wus2 with an Agrobacterium strain containing $\mathrm{Zm}$ Pltp $_{\text {pro: }}: \mathrm{Bbm}$ produced an unexpected response It was observed that a strong pulse of Wus 2 expression alone was enough to improve transformation and SC frequency (Table 1). The co-expression of the morphogenic genes from two different Agrobacterium strains was also evaluated, to characterize their effect on corn transformation. Immature embryos derived from PHIV69 were transformed with two Agrobacterium strains containing either PHP80912 ( $\mathrm{Zm}$ Pltp pro::Bbm plus marker genes), or PHP85848 ( $\mathrm{Zm}$ Pltp $p_{\text {pro }}:$ :Wus 2 plus marker genes) separately, or as mixtures. For the mixture, the two strains of Agrobacterium were individually adjusted to $\mathrm{OD}_{550}=0.5$ and mixed at a 1:1 ratio for immature embryo transformation. Embryos derived from four independent ears were split among the three treatments, using a minimum of 30 embryos/ear per treatment. Plants were regenerated and sampled for qPCR analysis for presence and copy number of Wus2, Bbm, or both (depending on the treatment). The frequency of recovering single-copy T0 plants (SC\%) was measured for each treatment and is summarized in Fig. 3 (with data for replicates within each treatment shown in Table S-4).

As predicted, $Z m-P l t p_{p r o}:: B b m$ alone transformed poorly and no SC events were recovered. As expected, $\mathrm{Zm}$ Pltp pro::Wus 2 produced several SC events in each replicate $(\overline{\mathbf{x}}=14.6 \%)$, with 38 total SC plants recovered. When the two Agrobacterium suspensions containing these two plasmids were mixed together in a 1:1 ratio, $25 \mathrm{SC}$ events were recovered that had only integrated the Zm-Pltp pro::Bbm TDNA $(\overline{\mathbf{x}}=11 \%)$, and $13 \mathrm{SC}$ events were recovered that only contained the Zm-Pltp pro::Wus2 T-DNA $(\overline{\mathbf{x}}=5.3 \%)$. In the Wus $2+B b m$ treatment, no transgenic events were recovered that contained both T-DNAs. In summary, $\mathrm{Zm}$ $P l t p_{p r o}:: B b m$ alone did not produce SC events, while $\mathrm{Zm}$ Pltp pro::Wus 2 effectively produced SC events, which was consistent with the data presented in Table 1 . Unexpectedly, the mixed Agrobacterium treatment resulted in the recovery of stable SC plants that either contained only Zm-Pltp pro::Bbm (with no Zm-Pltp pro::Wus2 integration), or contained Zm-Pltppro::Wus 2 . The frequency of SC $Z m-P l t p_{p r o}:: B b m$ plants was nearly twice the frequency of SC plants that contained Zm-Pltp pro::Wus 2 alone. Based on these results, it was hypothesized that the pulsed expression of Wus 2 stimulated somatic embryogenesis of adjacent cells that had stably integrated Zm-Pltp pro: :Bbm, which resulted in stable SC plant recovery. 


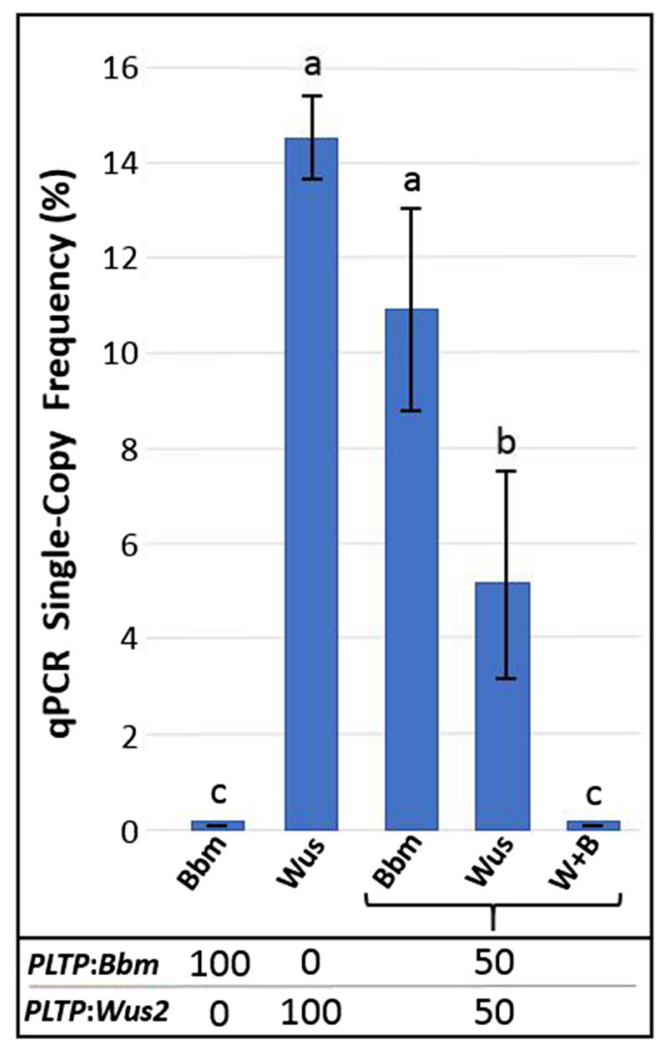

Figure 3. Single-copy frequencies for integrated T-DNAs containing either the Bbm gene (Bbm), the Wus2 gene (Wus), or the Bbm and Wus2 TDNAs $(\mathrm{W}+\mathrm{B})$ in T0 plants for maize inbred PH1V69. Zea mays (L) immature embryos from four ears were aliquoted into three batches, and transformed with 1 ) a single Agrobacterium strain containing PHP80912 (Zm-Pltp pro::Bbm); 2) a single Agrobacterium strain containing PHP85848 (Zm-Pltp pro::Wus2); or 3) with a 1:1 mixture of the two Agrobacterium strains. The three treatments are designated by the numbers at the bottom; Treatment $1(100 \%$ Bbm:0\% Wus2), Treatment $2(0 \%$ Bbm:100\% Wus2), and Treatment 3 (50\% Bbm:50\% Wus2). qPCR was used to determine the numbers of recovered T0 plants that were single copy (SC) for Bbm and Wus2, and the mean frequencies relative to the starting number of immature embryos are shown. Underneath the bars, acronyms indicate qPCR for $B b m$ and Wus 2 for the various treatments. $\mathrm{W}+\mathrm{B}$ stands for a single copy for both $\mathrm{Bbm}$ and $\mathrm{Wus} 2$. Letter designations above the bars signify whether the means for the treatments are significantly different (different letters), or not (same letter) with $p=0.05$. Single-Copy Transformation data for individual replicates within each treatment are shown in Table S-4.

Transformation with a mixture of one Agrobacterium strain containing an herbicide resistance marker and another Agrobacterium strain containing Zm-Pltp pro::Wus2 resulted in the recovery of events that contained only the selectable marker in a ratio-dependent manner To test the hypothesis that Wus2 stimulated somatic embryo formation in neighboring cells that had received only $B b m$, the experiment described previously was repeated, only replacing $\mathrm{Bbm}$ with the Selectable expression cassettes. To this end, a second Agrobacterium strain was engineered, which contained a TDNA binary plasmid harboring the Hra and Zs-GREEN expression cassettes (PHP86491, Fig. 4), without any morphogenic genes (no Bbm or Wus2). To improve the morphogenic stimulation, three caulimoviral enhancers from the Fig Wart Mosaic Virus, the Peanut Chlorotic Streak Virus, and the Mirabalis Mosaic Virus (the tandem enhancer being abbreviated as $3 \mathrm{xENH}$ ), were placed upstream to increase expression from the Zm-Pltp pro ::Wus2 expression cassette in the altruistic T-DNA (in PHP87078, see Fig. 4).

Agrobacterium strains containing either Hra + Zs-GREEN (Selectable), or $3 \mathrm{xENH}-$ Zm-Pltp pro $:: W u s 2$ (Wus2) were suspended in liquid, adjusted to the same density, and used with the Selectable alone (1:0 treatment), or in mixed ratios of 1:1, 9:1, and 99:1 (Selectable:Wus2). Next, the mixtures were used to transform HC69 immature embryos. As shown in Table 2, for the four treatments (1:0 Selectable alone, 1:1 Selectable to Wus2 ratio, 9:1 Selectable to Wus2 ratio, and 99:1 Selectable to Wus2 ratio), the overall transformation frequencies were 2.2, 9.2, 24.2, and 20.8\%, respectively [(\# Multi-copy + \# Singlecopy/\# Immature embryos)*100]. SC frequencies followed the same trend $(2.7,5.9,12.6$ and 6.8\%). All of the SC T0 plants contained only a single copy of the Selectable T-DNA without Wus2. Based on a confidence interval of 0.05 , all three Agrobacterium mixture ratios (1:1, 9:1, and 99:1), resulted in $\mathrm{SC} \%$ values that were similar to each other but significantly greater than the control (100\% Selectable vector). Cointegration frequencies were low to non-existent in the three treatments with mixed strains. In the first three treatments (Selectable alone, 1:1 and 9:1), wild-type non-transgenic plants were produced ("Num. Escape" in Table 2). In contrast, no escapes were observed in the 99:1 treatment.

In summary, the following trends were observed: (1) the addition of altruistic Wus2 increased the SC transformation frequencies of the stably integrated Selectable-containing ( $\mathrm{Hra}$ ) transgene for all the Agrobacterium mixtures when compared with Selectable T-DNA alone; (2) while all three dilutions were not statistically different, the mean SC\% for the 9:1 mixture appeared to provide the most practical treatment for further experimentation; and (3) very few of the plants were cotransformed (contained both T-DNAs). These data clearly demonstrated that strong transient expression of Wus 2 from the altruistic T-DNA stimulated somatic embryo formation in cells in which Wus 2 did not integrate, which resulted in the recovery of only Selectable T-DNA-containing T0 plants.

Trans acting recombinase activity indicated co-residence of both T-DNAs in a high frequency of "Selectable only" events When the two Agrobacterium strains were mixed at a ratio of 9:1 (Hra:Wus2), there were at least two possible mechanisms that could result in high-frequency somatic embryo formation containing only the selectable marker. Transient Wus 2 expression could occur in a cell receiving both T-DNAs with only the selectable marker integrating, and/or WUS2 protein could move from one cell into another cell containing only the Selectable T-DNA. To test this theory, an Agrobacterium 

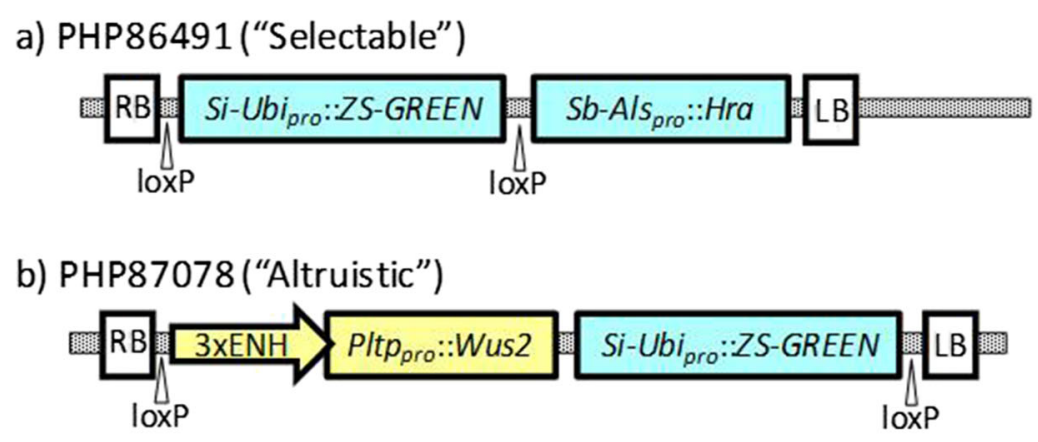

Figure 4. Constructs used in the experiment summarized in Table 2 below. The T-DNA within PHP86491 (a) contained constitutive ZSGREEN and an Hra expression cassette in which the Highly resistant Acetolactate synthase gene (Hra) was expressed behind the sorghum $A l s_{\text {pro }}$. The T-DNA within PHP87078 (b) contained a Wus2 expression

culture harboring the altruistic T-DNA (loxP $+3 \mathrm{xENH}:: \mathrm{Zm}-$

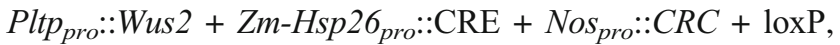
PHP87598), and an Agrobacterium strain harboring a TDNA with Hra plus a loxP-flanked Zs-GREEN (PHP86491, Fig. 5), were normalized to equal cell densities and mixed at ratios of 1:0, 1:1, and 9:1 before infecting HC69 immature embryos. As the Wus2-containing Agrobacterium was diluted with increasing amounts of Selectable T-DNA-containing Agrobacterium, a corresponding increase in the transformation frequency (Table 3) was observed. The highest dilution $(9: 1)$, resulted in a significantly higher frequency in T0 plants that contained a single copy (SC) of only the Selectable TDNA, relative to the Hra-alone (1:0) treatment (Table 3). Plants that contained only one copy of the Hra with or without $Z s-G R E E N$ (excised), and without the Agrobacterium

Table 2. Transformation data and the frequency of recovering SC integration events in Pioneer maize inbred HC69, after transformation with an Agrobacterium strain harboring a plasmid with a Selectable TDNA (PHP86491), or with a mixture of Selectable T-DNA cassette using the Zm-Pltp pro with three viral enhancer element upstream (abbreviated $3 \times E N H$ ), and the contituitive ZS-GREEN. The WUS2 expression cassette in the Altruistic T-DNA is highlighted in yellow, and due to the absence of $C R E$, no excision was expected.

backbone were scored as SC (Table 3). The frequency of SC events ranged from 1.6-6\%, with the highest frequency resulting from the highest dilution of the altruistic Agrobacterium. Co-transformed events were recovered in both the 1:1 and 9:1 treatments. Escapes were observed in all three treatments, but were readily eliminated before the plants were transferred to the greenhouse based on qPCR screening.

Surprisingly, when the results for the two "Mixed-Agro" treatments were combined, the Zs-GREEN marker was excised in approximately $42 \%$ of the recovered events that were $\mathrm{SC}$ for the Selectable T-DNA (based on the total number of $\mathrm{SC}-\mathrm{Hra}$ (No ZSG), relative to the total number of SC-Hra (both with and without ZSG). Because there were no Wus2 or $C R E$ sequences present in these cells, excision must have

Agrobacterium (Hra) and a second Agrobacterium strain harboring a TDNA containing plasmid with Wus2 (PHP87078). Transformation and single-copy data for individual replicates within each treatment are shown in Table S-5

\begin{tabular}{|c|c|c|c|c|c|c|c|c|c|}
\hline \multirow{2}{*}{$\begin{array}{l}\text { Agro. } \\
\text { strain(s) }\end{array}$} & \multirow{2}{*}{$\begin{array}{l}\text { Agro. } \\
\text { ratio }\end{array}$} & \multirow{2}{*}{$\begin{array}{l}\text { Number } \\
\text { imm. } \\
\text { embryo }\end{array}$} & \multirow{2}{*}{$\begin{array}{l}\text { Num. } \\
\text { plants }\end{array}$} & \multicolumn{4}{|c|}{ Determined using qPCR } & \multirow[t]{2}{*}{$\mathrm{SC} \% \overline{\mathrm{x}} \pm(\mathrm{SD})$} & \multirow[t]{2}{*}{ Sign. diff. } \\
\hline & & & & Num. escape & Num.MC & Num. Co-Tx & Num. SC & & \\
\hline $\mathrm{Hra}$ & $1: 0$ & 923 & 29 & 8 & 8 & NA & 13 & $2.7(3.1)$ & $\mathrm{a}$ \\
\hline$H r a+W u s 2$ & $1: 1$ & 260 & 44 & 16 & 11 & 4 & 13 & $5.9(6.1)$ & $\mathrm{b}$ \\
\hline$H r a+W u s 2$ & $9: 1$ & 289 & 84 & 12 & 42 & 2 & 28 & $12.6(4.2)$ & $\mathrm{b}$ \\
\hline$H r a+W u s 2$ & $99: 1$ & 230 & 48 & 0 & 30 & 0 & 18 & $6.8(5.3)$ & $\mathrm{b}$ \\
\hline
\end{tabular}

Agro ratio = ratio of Hra-Agro:Wus2-Agro used in the Agrobacterium mixture for transformation

Number imm. embryo = the number of immature embryos infected by the Agrobacterium

Num. plant $=$ the total number of plants recovered per treatment; Num. escapes $=$ the number of non-transgenic plants recovered per treatment

Num. $\mathrm{MC}=$ the number of plants containing multiple copies of transgenes and/or Agrobacterium plasmid backbone sequence

Num. Co-Tx $=$ the number of plants containing both the Selectable (Hra) and Altruistic (Wus2) T-DNA sequences

Num. $\mathrm{SC}=$ the number of T0 plants (events) that contained a single copy of the Wus2/Bbm T-DNA

$\mathrm{SC} \%=$ the frequency (mean \pm standard deviation) of single-copy T0 plants relative to the starting number of Agrobacterium-infected immature embryos (based on replicates in Table S-5)

Sign. diff. $=$ signifies whether the means for the treatments within an inbred are significantly different (different letters), or not (same letter) with $p=0.05$ 
a) PHP86491 ("Selectable")

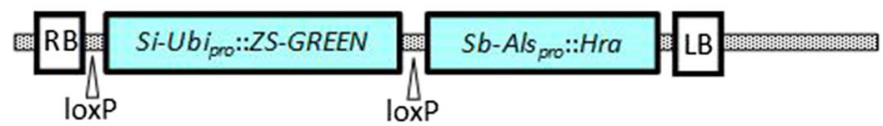

b) PHP87598 ("Altruistic")

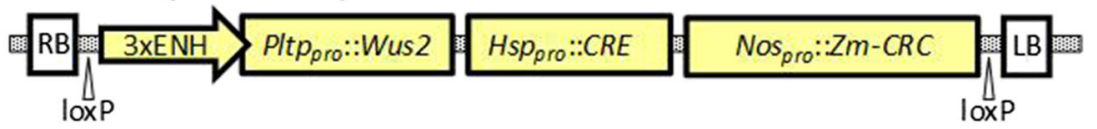

Figure 5. Constructs used in the experiment summarized in Table 3 below. The Selectable T-DNA within PHP86491 (a) contained ZS-GREEN (flanked by loxP recombination sites) and $\mathrm{Hra}$ (outside the loxP sites). The T-DNA within PHP87598 (b) contained a Wus2 expression cassette using the $3 \times E N H: P L T P_{\text {pro }}$, a Heat Shock Protein promoter $\left(H s p_{p r o}\right)$ driving expression of the $C R E$ recombinase and a constitutive promoter (Nos)

occurred even though the Wus2/CRE-containing T-DNA did not integrate. However, the presence of the three strong viral enhancer elements in the T-DNA, while not immediately adjacent to the $H s p 26_{\text {pro }}$, could have enhanced activity of the promoter in trans, as has been concluded in other studies (Weigel et al. 2000; Yoo et al. 2005; Gudynaite-Savitch et al. 2009). It should be emphasized that no heat driving expression of $C R C$. Expression cassettes within the Altruistic TDNA that could potentially be excised with exposure to CRE recombinase are highlighted in yellow. The feature labeled $3 \mathrm{xENH}$ is a fusion of three enhancer elements from plant viral promoters described in Table S1.

treatment was applied during this experiment (which normally stimulates the $\left.Z m-H s p 26_{p r o}\right)$. This suggested that $C R E$ recombinase activity had to be present due to transient expression from a non-integrated altruistic T-DNA. The remaining $58 \%$ of cells received the loxP-flanked Zs-GREEN T-DNA and produced transgenic plants. There are two explanations to describe this observation: 1) CRE
Table 3. Transformation data for maize inbred HC69 after infection with an Agrobacterium strain containing PHP86491, or after coinfection with mixtures of two Agrobacterium strains, one containing
PHP86491, and the second containing PHP87598 (mixed at two different ratios). Transformation and single-copy data for individual replicates within each treatment are shown in Table S-6

\begin{tabular}{|c|c|c|c|c|c|c|c|c|c|c|c|c|c|}
\hline \multirow{2}{*}{$\begin{array}{l}\text { Agro. } \\
\text { strain(s) }\end{array}$} & \multirow{2}{*}{$\begin{array}{l}\text { Agro. } \\
\text { ratio }\end{array}$} & \multirow{2}{*}{$\begin{array}{l}\text { Num. } \\
\text { embryos }\end{array}$} & \multirow{2}{*}{$\begin{array}{l}\text { Reg. } \\
\text { plants }\end{array}$} & \multicolumn{8}{|c|}{ Determined by qPCR } & \multirow[t]{2}{*}{$\mathrm{SC} \%$} & \multirow{2}{*}{$\begin{array}{l}\text { Sign. } \\
\text { diff. }\end{array}$} \\
\hline & & & & $\begin{array}{l}\text { Number } \\
\text { escapes }\end{array}$ & $\begin{array}{l}\text { Number } \\
\text { T0 PCR+ }\end{array}$ & $\begin{array}{l}\text { SC-HRA + } \\
\text { SC-ZSG }\end{array}$ & $\begin{array}{l}\text { SC-HRA } \\
\text { (no ZSG) }\end{array}$ & $\begin{array}{l}\text { Number } \\
\text { MC }\end{array}$ & $\begin{array}{l}\text { WUS } \\
\text { only }\end{array}$ & Co-Txn & $\begin{array}{l}\text { SC-HRA } \\
\text { BB- }\end{array}$ & & \\
\hline HRA & $1: 0$ & 321 & 61 & 39 & 22 & 6 & 0 & 16 & NA & NA & 6 & $1.6(1.4)$ & $\mathrm{a}$ \\
\hline HRA:WUS & $1: 1$ & 191 & 34 & 11 & 23 & 5 & 6 & 6 & 1 & 5 & 11 & $3.8(5.4)$ & $a, b$ \\
\hline HRA:WUS & $9: 1$ & 551 & 123 & 39 & 84 & 20 & 12 & 26 & 0 & 26 & 32 & $6.0(3.7)$ & $\mathrm{b}$ \\
\hline
\end{tabular}

Agro ratio = ratio of HRA-Agro:WUS-Agro used in the Agrobacterium mixture for transformation

Num. embryo $=$ the number of immature embryos infected by the Agrobacterium

Reg. plant $=$ the number of plants recovered per treatment

Number. escapes $=$ the number of non-transgenic plants recovered per treatment (containing no T-DNA sequences)

Number T0 PCR $+=$ the number of qPCR-positive plants for any of the transgenes within the two T-DNA sequences

$\mathrm{SC}-\mathrm{HRA}+\mathrm{SC}-\mathrm{ZSG}=$ the number of plants containing single copies of both Hra and Zs-GREEN

SC-HRA (no ZSG) $=$ the number of plants containing a single copy of $\mathrm{Hra}$ and no sequence from the Zs-GREEN T-DNA

Number. $\mathrm{MC}=$ the number of plants containing multiple copies of transgenes and/or Agrobacterium plasmid backbone sequence

WUS only = number of plants with only the Wus 2 expression cassette (possible due to T-DNA truncation)

$\mathrm{Co}-\mathrm{Tx}=$ the number of plants containing both the Selectable (Hra) and Altruistic (Wus2) T-DNA sequences, including both single- and multicopy integrations

SC-HRA BB- = the number of T0 plants (events) that contained a single copy of the Selectable T-DNA (Hra) with no Altruistic (Wus 2 ) sequence and no Agrobacterium backbone sequence

$\mathrm{SC} \%=$ the frequency of single-copy T0 plants relative to the starting number of Agrobacterium-infected immature embryos (mean \pm standard deviation, based treatment replicates in Table S-6)

Sign. diff. $=$ signifies whether the means for the treatments are significantly different (different letters) or not (same letter) with $p=0.05$ 
was insufficiently expressed in the co-infected cell, or the Selectable T-DNA-containing cell was not co-infected by the altruistic T-DNA; or 2) the Selectable-containing cell was stimulated to produce somatic embryos due to movement of WUS2 protein from adjoining cells, or its downstream mobile signaling pathway.

Adding CRC to the Wus2 helper vector eliminated cotransformed events without excision Encouraged by the results, an altruistic T-DNA vector was constructed (PHP88158), in which the CRE expression cassette had been removed (Fig. 6b), but the 3xENH: Zm-Pltp pro::Wus2 and a Nos ${ }_{p r o}:: C R C$ expression cassettes remained, with $C R C$ acting both as a color marker and a counter-selective agent. In addition to providing expression of Wus 2 at levels above Pltp alone, it was speculated that the $3 \mathrm{xENH}$ would also increase $C R C$ expression.

This new construct was tested in six new recalcitrant Pioneer inbreds (all normally non-transformable). Two liquid suspensions, one with the Selectable T-DNA-containing Agrobacterium strain (harboring PHP86491, Fig. 6a), and the other with the Wus2-containing Agrobacterium strain (harboring PHP88158), were normalized to an $\mathrm{OD}_{550}=0.5$. The two Agrobacterium suspensions were then mixed together at a ratio of 9:1 (Selectable:Wus2) and used to infect immature embryos from six different Pioneer maize inbreds, including one Pioneer temperate inbred (PHW52), two inbreds that are intermediate between temperate and tropical (PH2KD1 and PH28SV), and three tropical inbreds (all six inbreds not transformed previously). For all six inbreds, when a Selectable TDNA-containing (such as Hra or NPTII) Agrobacterium was used alone (without a Wus2 Agrobacterium strain), no transgenic events could be produced in these genotypes (data not shown). However, when a 9:1 mixture of Agrobacterium strains (Selectable/Wus2) was used, transformation frequencies for these inbreds ranged from 1.2 to $46 \%$, and T0 plants that contained a single copy for the selectable T-DNA ranged from 0 to 19.6\% (Table 4, and Table S-7). Co-transformation frequencies were low for all six inbreds. The few cotransformed plants obtained were easily identified by their deep red color. While unable to develop into healthy, fertile plants due to the presence of Wus 2 and $C R C$, abnormal plantlets with small, red leaves were sampled in culture for qPCR, which provided the co-transformation data.

To evaluate an alternative to $\mathrm{Hra}$ as the selectable marker, an Agrobacterium strain containing NPTII (PHP81561) in the Selectable T-DNA (Fig. 7a) was tested, along with the Agrobacterium strain carrying Wus2 (PHP88158), in the Altruistic T-DNA (Fig. 7b). After transformation, the transformed cells were selected on media supplemented with $150 \mathrm{mg} \mathrm{L}^{-1} \mathrm{G} 418$. As shown in Table 5, all six inbreds could be transformed using G418 selection. Compared with $\mathrm{Hra}$ (Table 4), the overall transformation frequency in all six inbreds appeared to be higher when NPTII was used as the selectable marker (Table 5), and SC T0 plants could be regenerated from all six inbreds. Importantly, while the use of NPTII and G418 selection improved transformation for all of the inbreds, the cotransformation frequency remained low (Table 5).

The growth response responsible for the observed low cotransformation frequencies shown in Tables 4 and 5 (using PHP 88158), is shown in Fig. 8. Seven days after Agrobacterium infection, numerous multicellular clusters of cells on the scutellar surface accumulated anthocyanin (Fig. $8 a$ ), while somatic embryo formation in surrounding tissues also occurred (yellow arrows) due to inferred expression of Wus2 from the anthocyanin co-expressing sectors. When transferred to embryo maturation medium, the somatic embryos continued to develop and regenerate (Fig. $8 b$ ) and produced vigorously growing plantlets that were anthocyanin-free, while additional growth in tissues with accumulated anthocyanin was inhibited. Therefore, the cells that integrated the Wus 2/CRC TDNA could produce somatic embryos but were incapable of regenerating normal plants, which was likely due to the enhanced expression of the transcription factors.

Successfully growing tropical plants (both wild-type and transgenic progeny) in the greenhouse is a challenge, because their photoperiod requirements are so different from the light conditions in a temperately located facility. Nonetheless, fertile T0 plants were produced in all six maize inbreds. For example, in the inbred PH2KD1, which is adapted to photoperiods that are intermediate compared with temperate or tropical inbreds,
Figure 6. Contructs used in the experiment summarized in Table 4 below. The T-DNA within PHP86491 (a) contained ZS-GREEN and $\mathrm{Hra}$, while PHP88158 (b) contained $3 \times$ ENH:Plt $t_{p r o}:$ Wus 2 and a constitutive promoter (Nos) driving expression of $C R C$. a) PHP86491 ("Selectable")

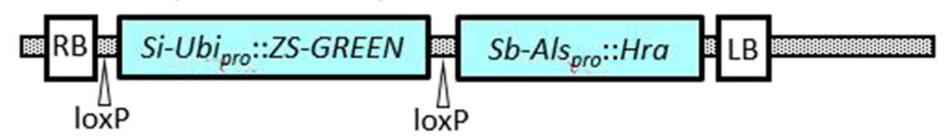

b) PHP88158 ("Altruistic")

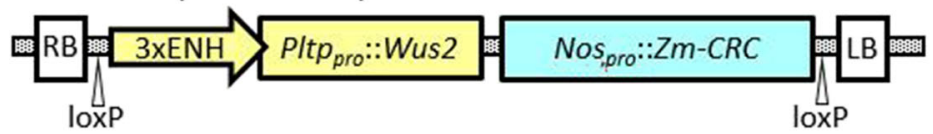


Table 4. Transformation frequency, single-copy frequency, and the number of co-transformed T0 maize plants recovered. Txn\% represents the frequency of $\mathrm{T} 0$ plants recovered (relative to the number of immature embryos infected), which contained only the Hra-containing T-DNA, after using a mixture of two Agrobacterium strains at a 9:1 ratio; the first with Hra for selection (in PHP86491), and the second that contained
$3 \times$ ENH:: Zm-Pltp pro $:: W u s 2$ in the T-DNA of PHP88158. Transformation data was based on both imazapyr-resistance and qPCR, while SC and Co-Txn determinations were based on qPCR data. Transformation and single-copy data for individual replicates within each treatment are shown in Table S-7

\begin{tabular}{|c|c|c|c|c|c|c|}
\hline \multirow[t]{2}{*}{ Inbred } & \multirow{2}{*}{$\begin{array}{l}\text { Immature } \\
\text { Embryos treated }\end{array}$} & \multicolumn{5}{|c|}{ Determined using qPCR } \\
\hline & & $\begin{array}{l}\text { Number of } \\
\text { HRA+ T0 plants }\end{array}$ & $\operatorname{Txn} \% \overline{\mathrm{x}} \pm(\mathrm{SD})$ & $\begin{array}{l}\text { Number } \\
\text { single-copy (SC) }\end{array}$ & $\mathrm{SC} \% \overline{\mathrm{x}} \pm(\mathrm{SD})$ & Number Co-Txn \\
\hline PHW52 & 339 & 157 & $46(16)$ & 56 & $12.4(8.8)$ & 0 \\
\hline PH2KD1 & 178 & 75 & $39(34)$ & 38 & $19.6(18.2)$ & 2 \\
\hline PH28SV & 61 & 1 & $1.2(1.1)$ & 0 & 0 & 0 \\
\hline PH4BAH & 72 & 22 & $34(30)$ & 8 & $11.1(5.8)$ & 0 \\
\hline PH2Y8G & 130 & 19 & $14(9)$ & 3 & $1.9(2.6)$ & 0 \\
\hline PH4B9Z & 109 & 7 & $4.5(6.2)$ & 1 & $1(1.9)$ & 1 \\
\hline
\end{tabular}

SC\% = Single-Copy Frequency for the Selectable T-DNA ( $\mathrm{Hr}$ ), relative to the Number of Immature Embryos

Number Co-Txn $=$ the number of T0 plants that had integrated both the HRA- and Wus2-containing T-DNAs

29 T0 plants from the NPTII/G418 experiment, and 29 plants from the $\mathrm{Hra}$ /imazapyr experiment were grown to maturity in the greenhouse. Of this total number for each set of plants, 21/ 29 and 25/29 plants set seed (respectively). Of the 21 (NPTII) and 25 ( $\mathrm{Hra}$ ) fertile ears, seed set was greater than 100 kernels/ ear in 21 ( 16 selfs and 5 pollinated with WT pollen), and 22 ears (13 selfs and 9 pollinated with WT pollen), respectively. For a second maize inbred (PH4BAH), which is a true tropical line, 18 plants in the NPTII experiment were grown in the greenhouse. Of these plants, 14 set seed, and six plants produced over 100 kernels/ear. For the Hra experiment, 10 plants were sent to the greenhouse, nine produced seed, and eight $\mathrm{T} 0$ plants had seed sets $>100$ kernels/ear. Robust fertility is a good indicator of overall plant vigor after transformation. Inbreds from temperate regions are adapted to the light conditions in the greenhouses used in this experiment, and plant vigor and fertility was very good, as has been previously reported (Lowe et al. 2016, 2018).

\section{Discussion}

When virulent Agrobacterium strains were used for plant transformation, it was observed that normal untransformed shoots and shooty teratomas would occasionally arise from Agrobacterium-derived tumors cultured on hormone-free medium (Aerts et al. 1979). Presumably, untransformed cells were able to proliferate on hormone-free medium due to stimulation by enhanced hormone production (auxin and cytokinin) from neighboring cells containing the T-DNA genes. These results were further exploited in transformation by mixing either a wild-type "armed," tumor-producing Agrobacterium strain (Depicker et al. 1985) or a partially armed Agrobacterium strain (that produced shooty growths), in combination with a disarmed Agrobacterium strain with or without a selectable marker (Brasileiro et al. 1991; Zambryski et al. 1984; Kuchuk et al. 1990; Aronen et al. 2002; Mihálka
Figure 7. Constructs used in the experiment summarized in Table 5 below. The T-DNA within PHP86491 (a) contained ZS-YELLOW and NPTII, while PHP88158 (b) contained $3 \mathrm{xENH}:$ Plt $t_{\text {pro }}::$ Wus 2 and Nos::CRC.

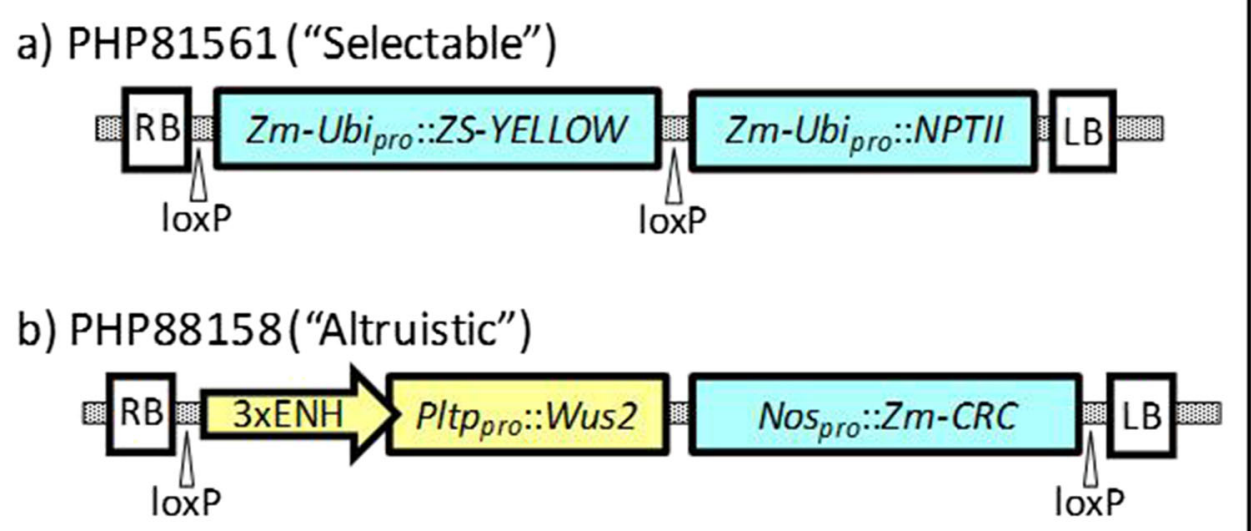


Table 5. Transformation frequency, single-copy frequency, and the number of co-transformed T0 maize plants recovered. Txn\% represents the frequency of $\mathrm{T} 0$ plants recovered (relative to the number of immature embryos infected), which contained only the NPTII-containing T-DNA, after using a mixture of two Agrobacterium strains at a 9:1 ratio; the first with NPTII for selection (in PHP81561), and the second that contained
3xENH:: Zm-Pltp pro::Wus2 in the T-DNA of PHP88158. Transformation data was based on both G418-resistance and qPCR, while SC and Co-Txn determinations were based on qPCR data. Transformation and singlecopy data for individual replicates within each treatment are shown in Table S-8

\begin{tabular}{lllllll}
\hline Inbred & $\begin{array}{l}\text { Immature } \\
\text { embryos treated }\end{array}$ & \multicolumn{2}{l}{ Determined using qPCR } \\
\cline { 3 - 7 } & & Number of NPTII+ T0 plants & Txn\% $\bar{x} \pm(\mathrm{SD})$ & Number single-copy (SC) & SC\% $\overline{\mathrm{x}} \pm(\mathrm{SD})$ & Number Co-Txn \\
\hline PHW52 & 331 & 223 & $77(32)$ & 45 & $7.4(7.4)$ & 1 \\
PH2KD1 & 167 & 89 & $53(32)$ & 32 & $16.2(17.3)$ & 0 \\
PH28SV & 62 & 7 & $16(9)$ & 2 & $4.3(2.9)$ & 0 \\
PH4BAH & 77 & 27 & $36(18)$ & 14 & $20.1(16.5)$ & 0 \\
PH2Y8G & 135 & 10 & $7(6)$ & 1 & $0.5(0.9)$ & 0 \\
PH4B9Z & 102 & 48 & $54(23)$ & 15 & $17.4(9.2)$ & 0 \\
\hline
\end{tabular}

${ }^{*} \mathrm{SC} \%=$ single-copy frequency for the Selectable T-DNA (NPTII), relative to the number of immature embryos. Number Co-Txn $=$ the number of T0 plants which had integrated both the NPTII- and Wus2-containing T-DNAs

et al. 2003). This allowed the recovery of T0 plants that contained only the T-DNA from the disarmed strain. As suggested by Mihálka et al. (2003), the recovery of transgenic
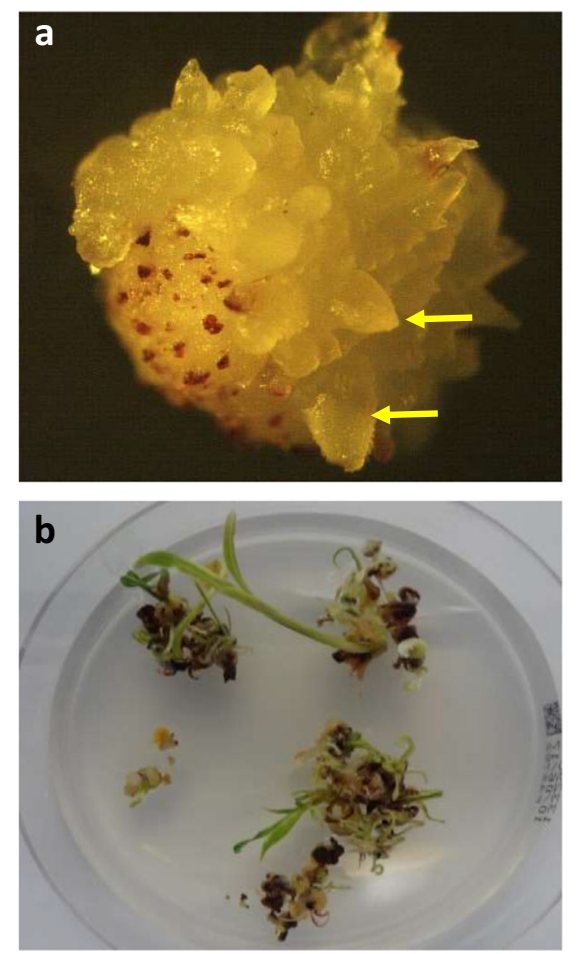

Figure 8. After co-transformation of tropical maize inbred PH2KD1 with two Agrobacterium strains at a ratio of $90 \%$ PHP 81561 and $10 \%$ PHP88158, multicellular clusters that contained anthocyanins due to $C R C$ expression can be observed in the lower left-hand quadrant of the originally transformed zygotic immature embryo $(a)$ with non-red somatic embryos forming nearby (yellow arrows). When transferred to embryo maturation medium, plantlets with no anthocyanin readily regenerated, while the growth of anthocyanin-containing tissues was inhibited (b). events could have occurred from the transient expression of the T-DNA genes on the armed (or partially armed) strain without its stable integration. Whereas Mihálka et al. (2003) used partially disarmed strains containing T-DNA with either auxin or cytokinin genes for transformation, in this study a disarmed Agrobacterium strain containing a T-DNA plasmid harboring the maize Wus2 expression cassette was used to stimulate somatic embryogenesis in neighboring cells and recover stable transgenic events.

As reviewed by Yau and Stewart (2013), mixed Agrobacterium strains have primarily been used to produce marker-free transgenic events. This has been accomplished either through co-transformation, in which the two independent transgenic loci would be segregated away from each other later in the process (Miller et al.; 2002; Komari et al. 1996), or through transient expression of the altruistic T-DNA (either hormone genes or selectable markers), for the direct production of marker-free transgenic events (Dutt et al. 2008; Gleave et al. 1999; Park et al. 2004). While the use of hormone-producing Agrobacterium strains to improve transformation has been useful in dicots, the utility in cereals has been minimal, due to the limited effect of cytokinins on somatic embryogenesis (the major route for cereal transformation).

Alternatively, transient expression of transcription factors to elicit an embryogenic response represents a viable alternative. Accordingly, Florez et al. (2015) used transient delivery of a transcription factor to stimulate embryo proliferation by introducing a T-DNA containing a $T c-B b m$ expression cassette into Theobroma cacao cotyledons cultured on hormone-free medium. Using this method, the authors elicited an embryogenic response, which ultimately regenerated non-transgenic plants (which was not possible without $T c-B b m$ ). Because phenotypically normal non-transgenic plants were produced, 
the authors speculated that a co-transformation approach could work to produce transgenic plants.

In maize, direct induction of somatic embryos capable of rapidly germinating from immature embryos (without a callus phase), using the auxin-inducible promoter Axigl driving Wus 2 in combination with $\mathrm{Bbm}$ driven by a maize Pltp promoter was reported previously (Lowe et al. 2018). This study demonstrated that the Pltp promoter driving Wus2 alone (with no $B b m$ ), is sufficient to rapidly induce somatic embryo formation on the scutellum of transformed zygotic immature maize embryos. As previously observed, ectopic expression of Wus 2 in maize scutella leads to cell divisions in neighboring cells and creates elongated meristem-like projections with the Wus 2 expressing cells embedded in the apex (Lowe et al. 2016). Based on these observations, it was hypothesized that transient Wus2 expression could stimulate growth in a noncell autonomous manner, and lead to embryogenesis and plant regeneration, making Wus2 an attractive candidate for use in an "altruistic transformation" approach.

The Pltp promoter has unique properties that make it desirable to drive morphogenic genes. It has been shown to be strongly expressed in the scutellar epithelial layer of embryos at the stage used for transformation, but is not expressed in early-stage embryos, meristems, roots, or reproductive tissues (Lowe et al. 2018). In previous studies, we used the Pltp promoter to express $\mathrm{Bbm}$ along with an auxin-inducible Wus 2 gene. In addition, the current results demonstrate that Zm-Pltp pro::Wus2 alone, is sufficient to directly produce somatic embryos without Bbm (Table 1).

The benefit of using Wus2 in an altruistic T-DNA was first recognized when maize immature embryos were cotransformed with a mixture of two Agrobacterium strains; the first containing Zm-Pltp pro::Wus2, and the second containing Zm-Pltp pro::Bbm in their respective T-DNAs. When strains containing either Zm-Pltp pro::Wus2 or Zm-Pltp pro::Bbm were used, only the Zm-Pltp pro::Wus 2 produced a high frequency of single-copy $\mathrm{T} 0$ plantlets, while few to none were produced by Zm-Pltp pro::Bbm alone (Table 1). However, when the two Agrobacterium strains were mixed at a 1:1 ratio, only the TDNA from the Agrobacterium strain containing $\mathrm{Zm}$ $P l t p_{p r o}:: B b m$ was integrated into a majority of the recovered plants. This result confirmed the hypothesis that expressed WUS2 protein was able to stimulate growth either through transient expression or by the movement of WUS2 into neighboring cells. The synergistic stimulation of somatic embryogenesis was demonstrated in previous studies, when Wus2 and $\mathrm{Bbm}$ integrated and expressed in the same cell (Lowe et al. 2016, 2018). This study demonstrated that the co-integration of the $B b m$ and Wus 2 expression cassettes in the same cell is not necessary. Through co-transformation experiments, it was shown that expression of Zm-Pltp pro::Wus2 alone was sufficient to produce somatic embryos and plants that only contained Zm-Pltp pro $:: B b m$. Based on this result, transient expression of Wus 2 alone could be used to recover T0 plants that contained other genes (without containing Wus2).

To test this hypothesis, an altruistic T-DNA vector was designed with high Wus2 expression that contained three strong viral enhancer sequences (from the Fig Wart Mosaic Virus, the Peanut Chlorotic Streak Virus, and the Mirabalis Mosaic Virus) upstream of the Zm-Pltp pro::Wus2 cassette, with no selectable marker in the T-DNA (PHP87078). It was previously determined that these viral enhancers in the proximity of Zm-Pltppro::Wus2 resulted in 'morphogenic toxicity' in the transgenic sectors expressing this cassette, which exhibited abnormal development that precluded further regeneration. Despite the abnormal growth patterns, it was hypothesized that the strongly enhanced promoter driving Wus2 expression would result in high concentrations of WUS2 protein, which would readily move into adjacent cells, and provide an even greater zone of regeneration competence. In addition to the Zm-Pltp pro::Wus2-containing Agrobacterium, $H r a$ or NPTII was substituted in place of $B b m$, to illustrate that using Wus 2 in a mixed-strain experiment can successfully be used to recover Wus2-free events. As shown in Table 2, transgenic events were recovered from all of the dilutions tested (mixing two Agrobacterium strains containing either PHP86491 or PHP87078), and although the numbers were small, the ratio of 9:1 (Hra/Wus2) produced the greatest increase in overall transformation frequencies and the number of single-copy events (SC\%), which contained only the Selectable T-DNA (from PHP86491). Interestingly, when other researchers used mixtures of a hormone-producing "shooty" strain with a disarmed strain that contained a TDNA, one group found that the ratio of disarmed strain to "shooty" strain was optimally 10:1 in poplar and wild cherry (Brasileiro 1991), while a similar comparison by another group using the same two "shooty" and disarmed Agrobacterium strains found that the control treatment, in which only the disarmed strain was used, was optimal in silver birch (Aronen et al. 2002).

The experiment in which the altruistic plasmid contained CRE recombinase on the T-DNA helped discern how the Wus2 altruistic method was working Table 3. In this experiment, the altruistic plasmid that contained $3 \times \mathrm{xENH}$ : $\mathrm{Zm}$ Pltp pro::Wus2, was followed by a heat-inducible promoter driving CRE recombinase plus the Nos $_{\text {pro }}:$ CRC expression cassette (PHP87598), and all three expression cassettes were located within the flanking loxP sites. The Selectable T-DNA contained a loxP-flanked $Z s-G R E E N$ along with a nonexcisable $\mathrm{Hra}$. When CRE was expressed, cassettes flanked by the loxP sites were excised and resulted in events with only the Selectable T-DNA. Consistent with these data low cotransformation frequencies were observed in this experiment, and there was no indication of the presence of the altruistic TDNA. It was observed that $3 \mathrm{xENH}$ not only stimulated the Pltp promoter but also presumably activated the downstream 
heat shock promoter driving $C R E$ recombinase, which resulted in the self-excision of the altruistic components. The contribution of the individual plasmids in the regenerating plantlets was determined using qPCR. Due to the auto-excision of loxP +3xENH: Zm-Pltp pro: :Wus2 + Hsp26 pro $:: C R E+$ $N o s_{p r o}:: C R C+$ loxP in the altruistic T-DNA, events were regenerated that were co-transformed with both T-DNAs, which predominantly contained only the portions of the altruistic TDNA remaining outside of the loxP sites after excision. Selectable events were also recovered, in which roughly half contained Hra, but had lost Zs-GREEN due to excision (with no detectable integration of the altruistic T-DNA containing an excision footprint). Because the CRE protein cannot move from cell-to-cell (Ströh et al. 2013; Martin-Ortigosa et al. 2014), the excised events that did not contain the $C R E$ expression cassette (originally from the altruistic T-DNA), could only have occurred if the T-strand did not integrate and CRE was expressed transiently. As speculated for other T-DNA configurations containing the $3 \mathrm{xENH}$ elements, these viral enhancers probably stimulated the Hsp26 promoter immediately when introduced into the cell, which was terminated during excision. This is consistent with observations by De Buck et al. (2000), in which transient CRE expression after co-transformation with two T-DNAs resulted in excision without the integration of CRE. This data with the Wus2-containing altruistic T-DNA vector, suggests two contributing modes of action for Wus2-stimulated somatic embryogenesis (Fig. 9). First, when cells transformed with either the Wus2 or the Hra
T-DNAs are in close proximity, the movement of WUS2 protein into the Hra T-DNA-containing cells may stimulate somatic embryogenesis in trans (Fig. 9a). Movement of WUS protein has been demonstrated as an important aspect of its morphogenic influence in the meristem (Yadev et al. 2011), but other localized changes such as alterations in growth regulators may also occur. Alternatively, when both T-DNAs are present in the same cell, transient Wus2 expression from the non-integrated Wus2-containing T-strand provides the necessary stimulation of somatic embryogenesis (Fig. 9b). This data is consistent with both explanations.

In the description of methods, chemical selection was applied during somatic embryo maturation and then continued into the germination and rooting stages of plantlet development, to reduce the recovery of wild-type non-transgenic (escape) plants. However, escapes were observed in Tables 2 and 3, but were not observed in Tables 4 and 5. This was a reflection of the baseline tissue culture response of the inbreds that were used in these experiments. HC69 (Tables 2 and 3) responds well in tissue culture, and this tendency is accentuated in non-transgenic cells by Altruistic Wus 2 expression from neighboring cells, even though a chemical selection is being applied. Higher concentrations of selective agents (or increasing the duration of selection) could eliminate this background, but were not tested in this study. In contrast, for the recalcitrant inbreds used in Tables 4 and 5, wild-type immature embryos did not produce a baseline culture response. While Altruistic Wus2 expression was still stimulating growth

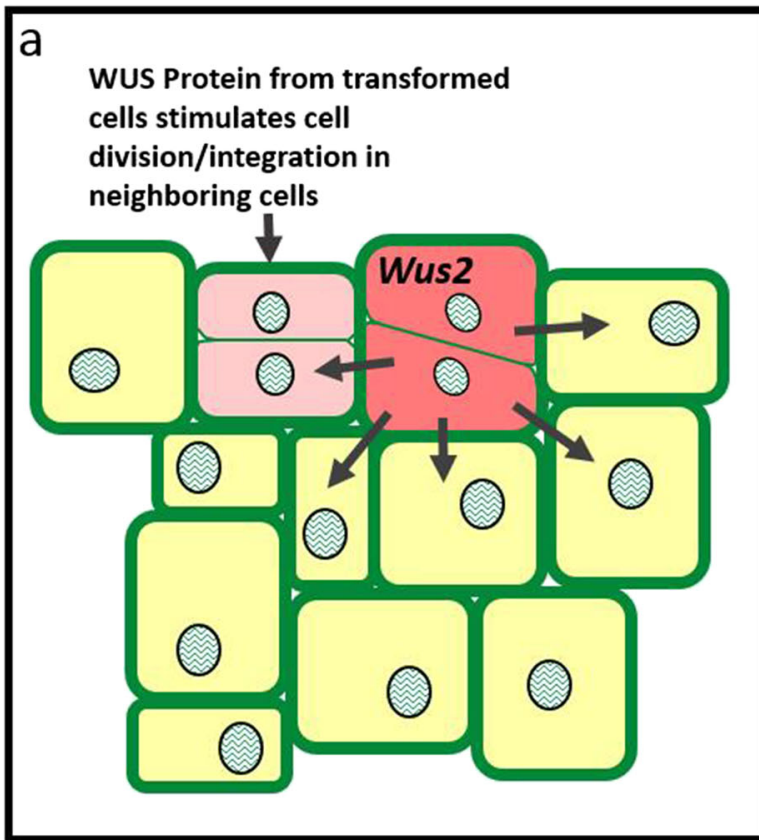

Figure 9. Two models for the mode-of-action of altruistic Wus2 Zea mays (L) transformation. (a) Movement of WUS protein stimulates cell division of neighboring cells that have independently integrated the Selectable T-DNA. (b) T-strands from both strains enter the cell, but only

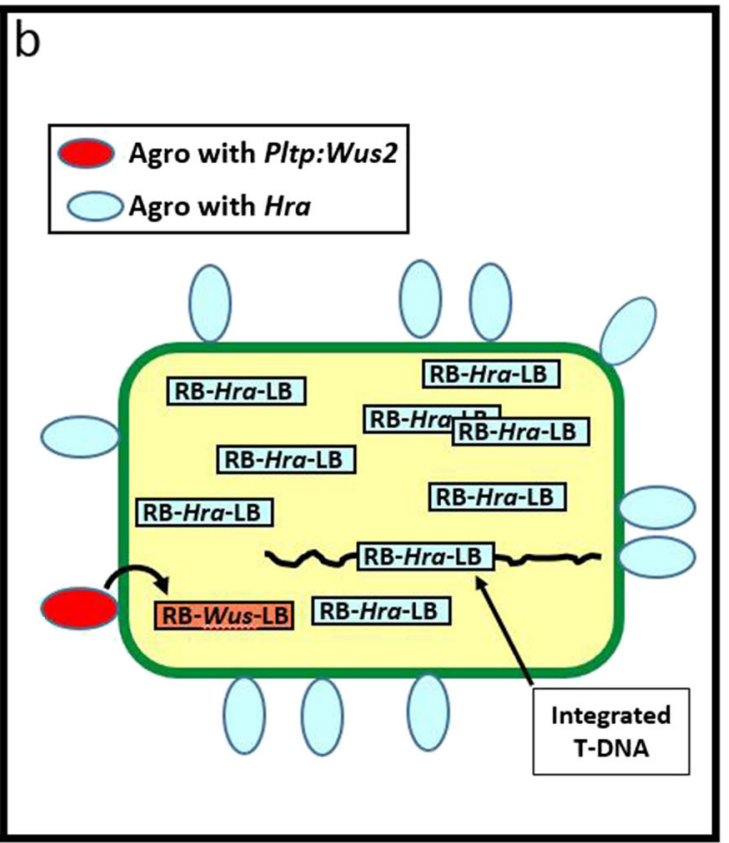

a fraction integrate. The ratios of the two Agrobacterium strains (9:1), favor integration of the T-DNA that contains the selectable marker, while the lower abundance of Wus2-containing T-strand permits transient Wus2 expression. 
in non-Wus 2 cells in these six inbreds, the addition of chemical selection was adequate to control background growth, and no escapes were recovered.

To ensure that recovered transgenic plants did not contain the Wus2/CRC T-DNA, an altruistic T-DNA was designed with a $N o s_{\text {pro }}:: C R C$ expression cassette, in addition to the 3xENH: Zm-Pltppro::Wus2 expression cassette without CREmediated excision. Normally, $\operatorname{Nos}_{p r o}:: C R C$ acts as a simple color marker as it directs the synthesis of red anthocyanin pigmentation. However, in this vector, it was expected that the expression of the $C R C$ expression cassette would be enhanced due to the nearby presence of the three viral enhancers. The high levels of anthocyanin produced with this construct were inhibitory and development was arrested. In conjunction with the negative pleiotropic effects due to Wus2 expression, the added stress imposed by anthocyanin accumulation resulted in an effective counter-selection against Wus2-containing cells (or somatic embryos), which helped to reduce the background of 'Selectable T-DNA' transformed lines that were also transformed with altruistic T-DNA. This altruistic transformation system is effective in sorghum (manuscript in progress) and, in principle, may be extended to any plant species that responds in a similar manner to over-expression of Wus2.

\section{Conclusions}

Despite improvements in transformation technologies for a small subset of plant species (such as maize), the availability of efficient transformation methods remains one of the remaining challenges for the plant transformation community, and represents the major impediment to genome editing in many crops (Altpeter et al. 2016). The use of morphogenic genes in both monocots and dicots has the potential to dramatically improve this situation (Gordon-Kamm et al. 2019). However, to date, strategies have focused on the use of single, complex T-DNAs that contain the morphogenic genes, and other genes such as selectable markers and/or traits, and components that will either excise or turn off the morphogenic genes later. These have been important first-generation methods that have demonstrated both increased transformation rates and extended genotype ranges. This study has demonstrated a viable second-generation alternative, which uses a mixture of an altruistic Wus2-containing Agrobacterium, and a separate selectable marker-containing Agrobacterium. This new method greatly simplifies vector construction, the tissue culture process, and downstream analysis of transgenic (or genome-modified) plants, and provides a more modular system to switch between different Wus2-containing and selectable marker-containing plasmids.

Open Access This article is licensed under a Creative Commons Attribution 4.0 International License, which permits use, sharing, adaptation, distribution and reproduction in any medium or format, as long as you give appropriate credit to the original author(s) and the source, provide a link to the Creative Commons licence, and indicate if changes were made. The images or other third party material in this article are included in the article's Creative Commons licence, unless indicated otherwise in a credit line to the material. If material is not included in the article's Creative Commons licence and your intended use is not permitted by statutory regulation or exceeds the permitted use, you will need to obtain permission directly from the copyright holder. To view a copy of this licence, visit http://creativecommons.org/licenses/by/4.0/.

\section{References}

Aerts M, Jacobs M, Hernalstreens JP, Van Montague M, Schell J (1979) Induction and in vitro culture of Arabidopsis thaliana crown gall tumours. Plant Sci Lett 17:43-50

Altpeter F, Springer NM, Bartley LE, Blechl AE, Brutnell TP, Citovsky V, Conrad LJ, Gelvin SB, Jackson DP, Kausch AP, Lemaux PG, Medford JI, Orozco-Cárdenas ML, Tricoli DM, Van Eck J, Voytas DF, Walbot V, Wang K, Zhang ZJ, Stewart CN (2016) Advancing crop transformation in the era of genome editing. Plant Cell 28: $1510-1520$

Anand A, Bass SH, Wu E, Wang N, McBride KE, Annaluru N, Miller M, Hua M, Jones TJ (2018) An improved ternary vector system for Agrobacterium-mediated rapid maize transformation. Plant Mol Biol 97:187-200

Aronen TS, Häggman JH, Häggman HM (2002) Applicability of the coinoculation technique using Agrobacterium tumefaciens shootytumour strain 82.139 in silver birch. Plant Cell Tissue Organ Cult 70:147-154

Brasileiro ACM, Leplé JC, Muzzin J, Ounnoughi D, Michel M-F, Jouanin L (1991) An alternative approach for gene transfer in trees using wild-type Agrobacterium strains. Plant Mol Biol 17:441-452

Bruce W, Folkerts O, Garnaat C, Crasta O, Roth B, Bowen B (2000) Expression profiling of the maize flavonoid pathway genes controlled by estradiol-inducible transcription factors $C R C$ and $\mathrm{P}$. Plant Cell 12:65-79

Chu UC, Adelberg J, Lowe K, Jones J (2019) Use of DoE methodology to optimize the regeneration of high-quality, single-copy transgenic Zea mays L. (maize) plants. In Vitro Cell Dev Biol Plant. https://doi. org/10.1007/s11627-019-10002-w

De Buck S, De Wilde C, Van Montagu M, Depicker A (2000) Determination of the T-DNA transfer and the T-DNA integration frequencies upon cocultivation of Arabidopsis thaliana root explants. Mol Plant Microbe Interact 13:658-665

Depicker A, Herman L, Jacobs A, Schell J, Van Montagu M (1985) Frequencies of simultaneous transformation with different TDNAs and their relevance to the Agrobacterium/plant cell interaction. Mol Gen Genet 201:477-484

Dutt M, Li ZT, Dhekney SA, Gray DJ (2008) A co-transformation system to produce transgenic grapevines free of marker genes. Plant Sci 175:423-430

Florez SL, Erwin RL, Maximova SN, Guiltinan MJ, Curtis WR (2015) Enhanced somatic embryogenesis in Theobroma cacao using the homologous BABY BOOM transcription factor. BMC Plant Biol 15:121-132

Gelvin SB (2003) Agrobacterium-mediated plant transformation: the biology behind the "gene-jockeying" tool. Microbiol Mol Biol Rev 67:16-37

Gleave AP, Mitra DS, Mudge SR, Morris BA (1999) Selectable markerfree transgenic plants without sexual crossing: transient expression of cre recombinase and use of a conditional lethal dominant gene. Plant Mol Biol 40:223-235

Gordon-Kamm B, Sardesai N, Arling M, Lowe K, Hoerster G, Betts S (2019) Using morphogenic genes to improve recovery and regeneration of transgenic plants. Plants 8:38 
Green JM, Hale T, Pagano MA, Andreassi JL, Gutteridge SA (2009) Response of 98140 corn with gat4621 and HRA transgenes to glyphosate and ALS-inhibiting herbicides. Weed Sci 57:142-148

Gudynaite-Savitch L, Johnson DA, Miki BLA (2009) Strategies to mitigate transgene promoter interactions. Plant Biotechnol J 7:472-485

Ishida Y, Saito H, Ohta S, Hiei Y, Komari T, Kumashiro T (1996) High efficiency transformation of maize (Zea mays L.) mediated by Agrobacterium tumefaciens. Nat Biotechnol 14:745-750

Jones T, Lowe K, Hoerster G, Anand A, Wu E, Wang N, Arling M, Lenderts B, Gordon-Kamm W (2019) Maize transformation using the morphogenic genes Baby Boom and Wuschel2. In: Transgenic Plants. Humana Press, New York, pp 81-93

Komari T, Hiei Y, Saito Y, Murai N, Kumashiro T (1996) Vectors carrying two separate T-DNAs for co-transformation of higher plants mediated by Agrobacterium tumefaciens and segregation of transformants free from selection markers. Plant J 10:165-174

Kuchuk N, Komarnitski I, Shakhovsky A, Gleba Y (1990) Genetic transformation of Medicago species by Agrobacterium tumefaciens and electroporation of protoplasts. Plant Cell Rep 8:660-663

Liu S, Kriz A, Duncan D, Widholm J (1998) Abscisic acid-regulated Glb1 transient expression in cultured maize P3377 cells. Plant Cell Rep 17:650-655

Livak KJ, Schmittgen TD (2001) Analysis of relative gene expression data using real-time quantitative PCR and the $2-\Delta \Delta \mathrm{CT}$ method. Methods 25:402-408

Lowe K, Wu E, Wang N, Hoerster G, Hastings C, Cho MJ, Scelonge C, Lenderts B, Chamberlin M, Cushatt J, Wang L, Ryan L, Khan T, Chow-Yiu J, Hua W, Yu M, Banh J, Brink K, Igo E, Rudrappa B, Shamseer PM, Bruce W, Newman L, Shen B, Zheng P, Bidney D, Falco C, Register J, Zhao Z-Y, Xu D, Jones T, Gordon-Kamm W (2016) Morphogenic regulators Baby boom and Wuschel improve monocot transformation. Plant Cell 28:1998-2015

Lowe K, La Rota M, Hoerster G, Hastings C, Wang N, Chamberlin M, Wu E, Jones T, Gordon-Kamm W (2018) Rapid genotype "independent" Zea mays L.(maize) transformation via direct somatic embryogenesis. In Vitro Cell Dev Biol Plant 54:240-252

Martin-Ortigosa S, Peterson DJ, Valenstein JS, Lin VS, Trewyn BG, Lyznik LA, Wang K (2014) Mesoporous silica nanoparticlemediated intracellular cre protein delivery for maize genome editing via loxP site excision. Plant Physiol 164:537-547

McCaw ME, Wallace JG, Albert PS, Buckler ES, Birchler JA (2016) Fastflowering mini-maize: seed to seed in 60 days. Genetics 204:35-42

Mihálka V, Balazs E, Nagy I (2003) Binary transformation systems based on 'shooter' mutants of Agrobacterium tumefaciens: a simple, efficient and universal gene transfer technology that permits marker gene elimination. Plant Cell Rep 21:778-784

Miller M, Tagliani L, Wang N, Berka B, Bidney D, Zhao ZY (2002) High efficiency transgene segregation in co-transformed maize plants using an agrobacterium tumefaciens 2 T-DNA binary system. Transgenic Res 11:381-396
Mookkan M, Nelson-Vasilchik K, Hague J, Zhang ZJ, Kausch AP (2017) Selectable marker independent transformation of recalcitrant maize inbred B73 and sorghum P898012 mediated by morphogenic regulators BABY BOOM and WUSCHEL2. Plant Cell Rep 36:14771491

Park J, Lee YK, Kang BK, Chung WI (2004) Co-transformation using a negative selectable marker gene for the production of selectable marker gene-free transgenic plants. Theor Appl Genet 109:15621567

Ströh S, Sonntag S, Janssen-Bienhold U, Schultz K, Cimiotti K, Weiler R, Willecke K, Dedek K (2013) Cell-specific cre recombinase expression allows selective ablation of glutamate receptors from mouse horizontal cells. PLoS One 8:e83076

Truett GE, Heeger P, Mynatt RL, Truett AA, Walker JA, Warman ML (2000) Preparation of PCR-quality mouse genomic DNA with hot sodium hydroxide and tris (HotSHOT). Biotechniq 29:52-54

Weigel D, Ahn JH, Blázquez MA, Borevitz JO, Christensen SK, Fankhauser C, Ferrándiz C, Kardailsky I, Malancharuvil EJ, Neff MM, Nguyen JT, Sato S, Wang Z-Y, Xia Y, Dixon RA, Harrison MJ, Lamb CJ, Yanofsky MF, Chory J (2000) Activation tagging in Arabidopsis. Plant Physiol 122:1003-1014

Wu E, Lenderts B, Glassma K, Berezowska-Kaniewska M, Christensen H, Asmus T, Zhen S, Chu U, Cho M-J, Zhao Z-Y (2014) Optimized Agrobacterium-mediated sorghum transformation protocol and molecular data of transgenic sorghum plants. In Vitro Cell Dev Biol Plant 50:9-18

Yadev RK, Perales M, Gruel J, Girke T, Jönsson H, Reddy GV (2011) WUSCHEL protein movement mediates stem cell homeostasis in the Arabidopsis shoot apex. Genes Dev 25:2025-2030

Yau YY, Stewart CN (2013) Less is more: strategies to remove marker genes from transgenic plants. BMC Biotechnol 13:36

Yoshioka Y, Takahashi Y, Matsuoka K, Nakamura K, Koizumi J, Kojima M, Machida Y (1996) Transient gene expression in plant cells mediated by Agrobacterium tumefaciens: application for the analysis of virulence loci. Plant Cell Physiol 37:782-789

Yoo SY, Bomblies K, Yoo SK, Yang JW, Choi MS, Lee JS, Weigel D, Ahn JH (2005) The 35S promoter used in a selectable marker gene of a plant transformation vector affects the expression of the transgene. Planta 221:523-530

Zambryski P, Herrera-Estrella L, De Block M, Van Montagu M, Schell J (1984) The use of the Ti plasmid of Agrobacterium to study the transfer and expression of foreign DNA in plant cells: new vectors and methods. In: Genetic engineering. Springer, Boston, pp 253278

Zhao Z-Y, Gu W, Cai T, Tagliani L, Hondred D, Bond D, Schroeder S, Rudert M, Pierce D (2002) High throughput genetic transformation mediated by Agrobacterium tumefaciens in maize. Mol Breed 8: $323-333$ 